\title{
CLINICAL CHARACTERISTICS AND MANAGEMENT OF Rh-D HAEMOLYTIC DISEASE OF NEWBORN
}

Sajith Vilambilin, Meena Dharmadas², Kumari Krishnakumariamma Chakrapani Usha ${ }^{3}$, Shaiji Panthiyil Shahulhameed ${ }^{4}$, Chitra James ${ }^{5}$, Anjaly Padmavilas Sasikala6, Soonam John ${ }^{7}$, Vineeth Rajagopal ${ }^{8}$

${ }^{1}$ Assistant Professor, Department of Transfusion Medicine, Government Medical College, Thrissur, Kerala.

2 Professor and HOD, Department of Transfusion Medicine, Government Medical College, Trivandrum, Kerala.

${ }^{3}$ Professor and HOD, Department of Transfusion Medicine, Sree Mookambika Institute of Medical Sciences, Kulasekharam,

Kanyakumari, Tamilnadu.

${ }^{4}$ Assistant Professor, Department of Transfusion Medicine, Government Medical College, Trivandrum, Kerala.

${ }^{5}$ Assistant Professor, Department of Transfusion Medicine, Government Medical College, Kollam, Kerala.

${ }^{6}$ Senior Resident, Department of Transfusion Medicine, Government Medical College, Thrissur, Kerala.

${ }^{7}$ Assistant Professor, Department of Transfusion Medicine, Government Medical College, Trivandrum, Kerala.

${ }^{8}$ Assistant Professor, Department of Family Medicine, Government Medical College, Calicut, Kerala.

\section{ABSTRACT}

\section{BACKGROUND}

In Rh-D haemolytic disease of foetus and newborn (HDFN), newborns can be severely affected, thereby associated with extensive morbidity and mortality.

Aim- The aim of this study is to describe the clinical profile of Rh-D HDFN.

Settings and Design- This was a descriptive study conducted in newborn, who had Rh-D HDFN. Setting was Depts. of Transfusion Medicine and Paediatrics in Govt. Medical College, Trivandrum.

\section{MATERIALS AND METHODS}

Enrolment of newborn was done according to inclusion criteria. Maternal and neonatal details were noted and risk of jaundice, severity of disease and intensity of treatment was assessed.

Statistical Analysis- All statistical data were analysed using SPSS software version 16.

\section{RESULTS}

29 (65.9\%) belonged to male gender and $15(34.1 \%)$ to female gender. The mean bilirubin levels in neonates on Day 1, 2, 3, 4 and 5 were 4.15, 6.66, 9.44, 11.1 and $11.14 \mathrm{mg} \%$ respectively; 20 (45.5\%) belonged to low risk, $13(29.5 \%)$ to low intermediate risk, 7 $(15.9 \%)$ to high intermediate risk and $4(9.1 \%)$ to high risk categories; 4 (9.1\%) belonged to no anaemia category, 17 (38.6\%) belonged to mild anaemia category, $19(43.2 \%)$ to moderate category and $4(9.1 \%)$ to severe category; 35 (79.5\%) of infants showed signs of haemolysis; $33(75 \%), 7(15.9 \%), 3(6.8 \%)$ and $1(2.3 \%)$ infants had mild, moderate, severe and very severe disease respectively; 20 (45.5\%) infants required no treatment; $13(29.5 \%)$ infants were treated only with phototherapy. IVIG was given along with phototherapy in 7 (15.9\%) infants; 4 (9.1\%) infants were treated with exchange transfusion along with IVIG and phototherapy. Neonates were transfused with 9 (20.5\%) packed red blood cells, 3 (6.8\%) platelets and 2 (4.5\%) fresh frozen plasma. Results of intensity of treatment was 20 (45.5\%) belonged to grade 0, $13(29.5 \%)$ to grade 1 category; 7 (15.9\%) fell into grade $2,3(6.8 \%)$ into grade 3 and $1(2.3 \%)$ into grade 4 category of treatment.

\section{CONCLUSION}

Male infants had higher risk of developing Rh-D HDFN. Majority of infants had mild hyperbilirubinaemia and anaemia only. Disease was mild among $3 / 4^{\text {th }}$ of infants and almost half of the infants required no treatment.

\section{KEYWORDS}

Haemolytic Disease of Foetus and Newborn, Hyperbilirubinaemia, Haemoglobin, Red Blood Cells, Platelets, FFP, Antigen, Antibody, Rh-D, Phototherapy, Intravenous Immunoglobulin, Exchange Transfusion.

HOW TO CITE THIS ARTICLE: Vilambil S, Dharmadas M, Usha KKC, et al. Clinical characteristics and management of RH-D haemolytic disease of newborn. J. Evolution Med. Dent. Sci. 2017;6(76):5425-5430, DOI: 10.14260/Jemds/2017/1177

\section{BACKGROUND}

Spectrum of neonatal haemolytic disease of foetus and newborn (HDFN) had faced profound and drastic transformations in the course of past 30 to 40 years. ${ }^{1}$

Financial or Other, Competing Interest: None.

Submission 08-07-2017, Peer Review 09-09-2017,

Acceptance 15-09-2017, Published 21-09-2017.

Corresponding Author:

Dr. Sajith Vilambil,

Assistant Professor

Department of Transfusion Medicine,

Government Medical College,

Thrissur-680596, Kerala.

E-mail: drsajithmenon@gmail.com

DOI: $10.14260 /$ jemds $/ 2017 / 1177$
In Rh-D alloimmunization newborns were often severely affected, unstable at birth, necessitated multiple exchange transfusions; thereby associated with extensive morbidity and mortality. Improved deliverance and appreciation of phototherapy, IVIG, exchange transfusion and RhIG had changed the picture dramatically. ${ }^{2}$

In countries with a low human development index antepartum treatment, improved neonatal surveillance and therapy had been established only to a limited degree.

Consequently, HDFN remained a major cause of morbidity and mortality in these countries. Thus, aim of this study was to describe the clinical profile of Rh-D HDFN for designing better management designs. 


\section{MATERIALS AND METHODS}

This was a descriptive study conducted in 44 neonates who were suffering from Rh-D HDFN. Research was done in Depts. of Transfusion Medicine and Paediatrics in Govt. Medical College, Trivandrum.

Enrolments of newborn were according to the inclusion criteria for a period of 18 months between 01-03-2012 and 30-08-2013.

\section{Inclusion Criteria for Rh-D HDFN}

1. Maternal antibody screen positive for anti-D and presence of $\mathrm{D}$ antigen in neonate.

2. Between mother and neonate, there should be no ABO incompatibility.

3. DAT and elution positivity in neonate.

4. Increased bilirubin levels in first 24 hours of birth.

5. No other aetiological feature for hyperbilirubinaemia.

Features of HDFN in presence of jaundice due to other illness was excluded.

Demographic details and maternal details such as age, blood group, parity, history of transfusion, abortion, IUD, ectopic pregnancy, amniocentesis, neonatal jaundice in previous delivery, IVIG administration, chronic disease, chronic infection and intrauterine transfusion were noticed. Mode of delivery and birth details including as birth weight, maturity, gender, APGAR score and feeding pattern were noted down.

Increased bilirubin levels were classified using chart provided by American Academy of Paediatricians (AAP). Investigations such as blood group of neonate, reticulocyte count, peripheral smear, haemoglobin and bilirubin levels were recorded. Grading of anaemia was performed according to the description in Wintrobe's Haematology ${ }^{3}$ (No-Hb $\geq$ 17g\%, Mild-Hb 14 - 17g\%, Moderate-Hb 12 - 14g\%, Severe$\mathrm{Hb}<12 \mathrm{~g} \%$ ).

According to AAP chart risk related to peak bilirubin values were categorised. Grading of disease as mild, moderate, severe and very severe was done according to the proposal by Andrew et al. ${ }^{4}$ (Mild-Grade 0; $\mathrm{Hb}>12.5 \mathrm{~g} / \mathrm{dL}$, no transfusions, Moderate-Grade $1: \mathrm{Hb}>12.5 \mathrm{~g} / \mathrm{dL}+$ top-up or exchange transfusion, Severe-Grade $2: \mathrm{Hb}<12.5 \mathrm{~g} / \mathrm{dL}+$ exchange transfusion, Very Severe-Grade 3: intrauterine transfusions and/or $\mathrm{Hb}<10.0 \mathrm{~g} / \mathrm{dL} \pm$ exchange transfusions or foetal death).

Details of phototherapy, IVIG, exchange and top-up transfusion with blood components were documented. Treatment was graded as described in book of Wintrobe's Haematology. ${ }^{5}$ (Grade 0- no treatment, Grade 1phototherapy alone, Grade 2- phototherapy plus IVIG, Grade 3- phototherapy, IVIG plus single exchange transfusion, Grade 4- phototherapy, IVIG plus multiple exchange transfusions).

Treatment duration and status of survival of the neonate were recorded. Haemoglobin and bilirubin levels of neonates were performed on $14^{\text {th }}$ day in review clinic.

\section{Ethics}

Human Ethical Committee and Review Board of Institution had approved the research. Parents of all newborn were counselled about the study. A written consent was obtained from all of them.

\section{Statistical Analysis}

Analysis of statistical data was done with SPSS software version 16. Continuous variables were expressed as mean \pm standard deviation and qualitative data as frequencies and percentages. Chi-square test was done for comparison of categorical variables. Correlation between variables was done using spearman correlation test. $\mathrm{P}$ values were two tailed and $<0.05$ was considered statistically significant.

\section{RESULTS}

Among the mothers of infants with Rh-D HDFN 9 (20.5\%) belonged to $18-22$ years, 17 (38.6\%) belonged to $23-27$ years, $11(25 \%)$ belonged to 28 - 32 years, $6(13.6 \%)$ belonged to $33-37$ years and $1(2.3 \%)$ belonged to $38-42$ years. Mean maternal age was $27 \pm 5.06$. The minimum and maximum age of mothers was 18 and 39 years respectively.

Regarding the parity of mothers, $1(2.3 \%)$ belonged to primigravida, $26(59.1 \%)$ to second gravida, $12(27.3 \%)$ to third gravida and $5(11.3 \%)$ to fourth gravida. In mothers of infants with Rh-D HDFN, there were 2 cases of previous blood transfusion (4.5\%), 14 abortions (31.8\%), 9 neonatal jaundiced babies (20.5\%), 11 IVIG injections (25\%), 4 intrauterine deaths $(9.1 \%), 1$ ectopic pregnancy $(2.3 \%), 5$ neonatal deaths (11.4\%), 1 case of diabetes mellitus $(2.25 \%)$, 1 case of psoriasis $(2.25 \%)$ and 1 case of hepatitis $(2.3 \%)$.

There were 14 (31.8\%) vaginal deliveries, 16 (36.4\%) induced vaginal deliveries and 14 (31.8\%) caesarean sections; 29 (65.9\%) belonged to male gender and 15 (34.1\%) to female gender.

In infants with Rh-D HDFN 27 (61.4\%) were with birth weight of $2500 \mathrm{~g}$ or more and $17(38.6 \%)$ with birth weight less than $2500 \mathrm{~g} ; 39$ (88.6\%) were term babies and 5 (11.4\%) preterm babies; 39 (88.6\%) were with APGAR score 7 - 10, 3 $(6.8 \%)$ with $4-6$ and 2 (4.6\%) with 3 or lesser; 34 (77.3\%) neonates were fed with breast milk, 6 (13.6\%) with both breast milk and formula feed and 4 (9.1\%) with formula feed alone.

Mean bilirubin values in newborn on Day 1, 2, 3, 4 and 5 were $4.15,6.66,9.44,11.1$ and $11.14 \mathrm{mg} \%$ respectively. Out of the 44 infants with Rh-D HDFN 20 (45.5\%) belonged to low risk, $13(29.5 \%)$ to low intermediate risk, 7 (15.9\%) to high intermediate risk and $4(9.1 \%)$ to high risk categories. The mean cord blood bilirubin level was $4.148 \pm 1.104$. Minimum and maximum bilirubin levels were $1.8 \mathrm{mg} \%$ and $8.8 \mathrm{mg} \%$ respectively.

\begin{tabular}{|c|c|c|}
\hline Level of Risk & Frequency & Percentage \\
\hline Low risk & 20 & 45.5 \\
\hline Low intermediate risk & 13 & 29.5 \\
\hline High intermediate risk & 7 & 15.9 \\
\hline High risk & 4 & 9.1 \\
\hline Total & $\mathbf{4 4}$ & $\mathbf{1 0 0 . 0}$ \\
\hline \multicolumn{2}{|c|}{ Table 1. Risk Related to Peak Bilirubin Levels } \\
\hline
\end{tabular}

Among infants $4(9.1 \%)$ belonged to no anaemia category, $17(38.6 \%)$ belonged to mild anaemia category, $19(43.2 \%)$ to moderate category and $4(9.1 \%)$ to severe category. Mean cord blood haemoglobin level was $14.470 \pm 1.975$. Minimum haemoglobin level was $9.8 \mathrm{~g} \%$ and maximum was $17.7 \mathrm{~g} \%$. 


\begin{tabular}{|c|c|c|}
\hline Grading of Anaemia & Frequency & Percentage \\
\hline No anaemia & 4 & 9.1 \\
\hline Mild & 17 & 38.6 \\
\hline Moderate & 19 & 43.2 \\
\hline Severe & 4 & 9.1 \\
\hline Total & $\mathbf{4 4}$ & $\mathbf{1 0 0 . 0}$ \\
\hline \multicolumn{2}{|c|}{ Table 2. Grading of Anaemia in Infants with HDFN }
\end{tabular}

Reticulocyte count was $\geq 4.6$ in $38(86.4 \%)$ and $<4.6$ in 6 $(13.6 \%)$ neonates; 35 (79.5\%) of infants showed signs of haemolysis in peripheral smear, whereas 9 (20.5\%) did not show any signs of haemolysis.

33 (75\%), 7 (15.9\%), 3 (6.8\%) and 1 (2.3\%) infants had mild, moderate, severe and very severe disease respectively; $20(45.5 \%)$ infants required no treatment. Phototherapy alone was the modality of treatment in 13 (29.5\%) infants. IVIG was administered along with phototherapy in 7 (15.9\%) infants; 4 (9.1\%) infants required exchange transfusion in addition to IVIG and phototherapy.

\begin{tabular}{|c|c|c|}
\hline Grade & Frequency & Percentage \\
\hline Mild & 33 & 75.0 \\
\hline Moderate & 7 & 15.9 \\
\hline Severe & 3 & 6.8 \\
\hline Very Severe & 1 & 2.3 \\
\hline Total & $\mathbf{4 4}$ & $\mathbf{1 0 0 . 0}$ \\
\hline \multicolumn{2}{|c|}{ Table 3. Severity of HDFN } \\
\end{tabular}

\begin{tabular}{|c|c|c|}
\hline Treatment Modalities & Frequency & Percentage \\
\hline No treatment & 20 & 45.5 \\
\hline Phototherapy alone & 13 & 29.5 \\
\hline Phototherapy and IVIG & 7 & 15.9 \\
\hline $\begin{array}{c}\text { Exchange transfusion, IVIG } \\
\text { and Phototherapy }\end{array}$ & 4 & 9.1 \\
\hline Total & $\mathbf{4 4}$ & $\mathbf{1 0 0 . 0}$ \\
\hline Table 4. Treatment Modalities in Infants with HDFN \\
\hline
\end{tabular}

Regarding blood product transfusion, 9 (20.5\%) transfused packed red blood cells, 3 (6.8\%) transfused platelet concentrate and $2(4.5 \%)$ transfused fresh frozen plasma. Results of intensity of treatment was 20 (45.5\%) belonged to grade $0,13(29.5 \%)$ to grade $1,7(15.9 \%)$ to grade $2,3(6.8 \%)$ grade 3 and $1(2.3 \%)$ to grade 4 category of treatment.

In infants with Rh-D HDFN 20 (45.5\%), 2 (4.5\%), 8 (18.2\%), 4 (9.1\%), 3 (6.8\%), 5 (11.3\%), 1 (2.3\%) and 1 $(2.3 \%)$ had undergone $0,3,4,5,6,7,8$ and 9 days of treatment respectively. Among infants 22 (50\%), 6 (13.6\%), 5 (11.4\%), 1 (2.3\%), 3 (6.8\%), 3 (6.8\%), 1 (2.3\%), 2 (4.5\%) and $1(2.3 \%)$ had stayed in ICU 5, 6, 7, 8, 9, 10, 12, 14 and 15 days of ICU stay respectively. Mean treatment duration was $2.91 \pm$ 2.94 days. Median and maximum treatment duration was 3.5 and 9 days respectively. Mean duration of stay in ICU was $6.84 \pm 2.73$ days. The range of stay in ICU was $5-15$ days.

During follow-up after two weeks, hyperbilirubinaemia was detected in 2 (4.5\%) infants; $1(2.3 \%)$ of the infants was anaemic. All three infants were readmitted for treatment. Three neonates did not attend follow-up clinic; 1 (2.3\%) infant with Rh-D HDFN died.

Association between high bilirubin levels and anaemia was done by chi-square test. Those newborn categorised under high risk and high intermediate risk categories in AAP grading were considered as high bilirubin group. Those categorised under low intermediate risk and low risk categories were considered as low bilirubin group. $\mathrm{P}$ value was 0.004 , which was significant. High bilirubin level was associated with 2.3 times higher risk for moderate and severe anaemia in neonates affected with Rh-D HDFN. Odds ratio was 2.308 and confidence interval was $1.453-3.665$.

Association between anaemia and duration of stay of infants with Rh-D HDFN in ICU for more than one week was assessed using chi-square test. $\mathrm{P}$ value was 0.004 , which was significant.

Anaemia was associated with 9.1 times higher risk for stay in ICU for more than one week in neonates affected with Rh-D HDFN. Odds ratio was 9.130 and confidence interval was 1.275 - 65.384.

Association between high bilirubin levels and signs of haemolysis was assessed using chi-square test. No significant risk was found in the test.

In Rh-D HDFN cord blood haemoglobin levels were negatively correlated with treatment intensity and disease severity ( $p$ value of 0.001 ). Correlation was significant at the 0.01 level.

In Rh-D HDFN risk of peak bilirubin levels was positively correlated with severity of disease, intensity of treatment and stay in ICU. Significant negative correlation was observed between risk of peak bilirubin levels and cord blood haemoglobin. Correlation was significant at the 0.01 level.

\section{DISCUSSION}

44 neonates admitted in NICU with Rh-D HDFN were included in the study. Most of the mothers were multiparae (97.7\%). For immune antibodies causing HDFN, there should be a sensitising event such as transfusion, pregnancy or abortion.

Similar findings were obtained in our study too. Literature points out that the first D positive infant born in a previously unimmunised woman might have a positive DAT, but very seldom showed clinical signs of haemolytic disease. ${ }^{6}$

Even if affected, haemolytic disease in the first affected infant was less severe when compared to subsequently affected siblings. ${ }^{7}$ In our study, a single case of Rh-D HDFN occurred in a primigravida who was previously sensitised by an out of group platelet transfusion for dengue haemorrhagic fever two years back.

Nevanlinna had opined that the severity of HDFN in first affected infant born to a previously transfused mother was presumably greater since transfusion appeared to be a more sensitising factor than TPH. ${ }^{8}$

In this study, abortion was found in a higher rate among mothers of infants with Rh-D HDFN (31.8\%). In a research by Grant et al, it was found out that the overall risk of immunization following induced abortion in a $\mathrm{D}$ negative woman was $4 \%{ }^{9}$

After an induced abortion in D negative primiparae, the frequency of anti-D in succeeding pregnancy was $1.5 \%$ within first 3 months and $3.1 \%$ by term. ${ }^{10,11}$

Risk of D immunization following amniocentesis was greater and Grant et al observed that the maternal anti-D concentration increased rapidly after procedure. ${ }^{12}$ But in our study, no woman had undergone amniocentesis in present or previous pregnancies. 
In a study by Warren RC et al, no foetal red cells were detected by acid-elution method in 161 mothers who had undergone chorionic villus sampling at 7 - 14 weeks. ${ }^{13}$

Walker et al noticed that the risk of stillbirth in a woman who previously delivered mildly affected infant was $2 \%$, whereas in a woman who delivered one previous stillbirth was as high as $70 \% .^{7}$

In this analysis, eleven mothers of infants with Rh-D HDFN had undergone postpartum RhIG prophylaxis during previous deliveries. Since intrauterine transfusion was not practiced in study setting, there was no single foetus that had undergone the same.

Mothers of infants with Rh-D HDFN underwent induced vaginal $(36.4 \%)$ and caesarean section $(31.8 \%)$ in a higher rate, probably because of an expectant HDFN in Rh incompatible deliveries. Bowman suggested that if history, antibody levels and amniotic fluid measurements had indicated that the foetus was only mildly affected, delivery should be allowed to take place spontaneously.

At the same time, Allen FH Jr. has opined that $50 \%$ of all stillbirths due to haemolytic disease occurred after 35 weeks gestation. ${ }^{14}$ Walker et al have further added that the delivery carried out on 30 - 32 weeks had high survival rates.

$65.9 \%$ of infants were males in Rh-D HDFN. A cluster of studies had showed that the D positive male infant initiated Rh-D immunization more frequently than female counterpart; the sex ratio ranged from $1.44-1.74: 1$ in different studies. ${ }^{15,16,17}$

Among $44 \mathrm{D}$ positive neonates with Rh-D HDFN, 45.5\% had low risk, $29.5 \%$ had low intermediate risk, $15.9 \%$ had high intermediate risk and $9.1 \%$ had high risk related to bilirubin levels. In infants with Rh-D HDFN, risk related to peak bilirubin levels exhibited a significant positive correlation with severity of disease, intensity of treatment and duration of stay in ICU and negative correlation with umbilical cord blood haemoglobin.

Mollison et al and Ackerman et al explained a correlation between cord bilirubin concentration and severity and a close relationship between peak serum bilirubin concentration and development of kernicterus. ${ }^{18,19}$

But Karel Polacek noticed that even though the cord blood bilirubin levels were always increased in infants with Rh-D HDFN, their prognostic significance were not as clear as that of the haemoglobin concentration. ${ }^{20}$

Mollison and Cutbush noticed a close relationship between peak serum bilirubin concentration and development of kernicterus. ${ }^{21}$ In mature infants, kernicterus seldom developed when serum bilirubin concentrations were less than $18 \mathrm{mg} / \mathrm{dL} .{ }^{22}$ Karel Polacek opined that the bilirubin levels were always increased in cord blood of affected neonates and it was useful in deciding treatment modalities. ${ }^{22}$

In present research, majority fell in mild or moderate anaemia categories. Bowman noticed that in infants with RhD HDFN, $50 \%$ of DAT positive infants had mild anaemia and hyperbilirubinaemia, $25 \%$ had severe disease and the remaining $20 \%$ to $25 \%$ had very severe disease. ${ }^{23}$

Likewise, in our study $45.7 \%$ of infants with Rh-D HDFN had no or mild anaemia and $25.1 \%$ had severe disease. In our research, in Rh-D HDFN higher bilirubin level was found to be a risk factor for occurrence of anaemia.
Nicolaides $\mathrm{KH}$ opined that in infants with more severe haemolytic process, profound anaemia developed in-utero and hydrops foetalis occurred when foetal haemoglobin deficit exceeded $7 \mathrm{~g} / \mathrm{dL}$.

Levine had concluded that the best criterion to assess severity of haemolytic disease was cord haemoglobin concentration. $^{24}$ Armitage had observed that before introduction of immunoprophylaxis, almost $50 \%$ of affected infants had cord haemoglobin concentrations of $14.5 \mathrm{~g} / \mathrm{dL}$ or more, $30 \%$ had $10.5-14.4 \mathrm{~g} / \mathrm{dL}$ and about $20 \%$ had $3.4-10.4$ g/dL. ${ }^{25}$

Mollison pointed out that the probability of survival diminished as the cord haemoglobin concentration dropped. Mollison and Cutbush found out that cord haemoglobin concentration was strongly correlated with disease severity as compared to cord bilirubin levels. ${ }^{26}$

Crawford et al observed a minor increase in osmotic fragility and spherocytosis in severe cases of Rh-D haemolytic disease. ${ }^{27}$ Hughes Jones et al detected 0.4 to $18.0 \mu \mathrm{g}$ of anti-D per $\mathrm{mL}$ of cord blood cells, which was not correlating with cord haemoglobin or bilirubin concentration. ${ }^{28}$

In this study, haemoglobin levels displayed a significant negative correlation with intensity of treatment. Close negative correlation between the haemoglobin concentration in cord blood and the infant's chance of survival was demonstrated by Mollison and Cutbush. ${ }^{19}$

Reticulocyte count was increased in $86.4 \%$ of neonates with Rh-D HDFN. Crawford et al witnessed that a slight increase in reticulocytes was a common feature in HDFN and in an analysis by Levine et al, reticulocyte count exceeded $15 \%$ in $54.5 \%$ of neonates. ${ }^{29,30}$ Signs of haemolysis were seen in $79.5 \%$ of infants who underwent this study.

Few researchers reviewed that in Rh-D HDFN, the severity of haematologic abnormalities were directly proportional to the severity of haemolysis and the extent of haematopoiesis. But in this research, high bilirubin level was not associated significantly with degree of haemolysis.

Cremer opined that exposure to light with a wavelength of $420-480 \mathrm{~nm}$ would help to convert toxic bilirubin to nontoxic bilirubin. ${ }^{31}$ Peterec observed that serum bilirubin declined by $0.5-1 \mathrm{mg} / \mathrm{dL}$ in the first $4-8$ hours on intensive phototherapy. ${ }^{32}$

Eugene et al opined that early phototherapy usually reduced or prevented a further rise in serum bilirubin levels and most of the neonates required no transfusions. ${ }^{33}$ This research also yielded similar results.

Phototherapy, IVIG and exchange transfusions were collectively administered to $9.1 \%$ of neonates with Rh-D HDFN. American Academy of Paediatrics says that the use of IVIG in a single or multiple dose regimen had been able to effectively reduce need for exchange transfusion, duration of phototherapy and hospital stay. ${ }^{32}$

Rubo et al observed that exchange transfusion was required in 11 out of 16 infants receiving phototherapy alone and 2 out of 16 infants receiving phototherapy and high-dose IVIG. ${ }^{34}$

Although, IVIG was proven to be safe, a retrospective review by Figueras Aloy et al had reported that it carried an increased risk of necrotising enterocolitis in late preterm and term infants. ${ }^{35}$ 
Exchange transfusion with $\mathrm{D}$ negative blood greatly increased the survival rate and almost removed the risk of kernicterus. ${ }^{36}$ Harvey Klein and David Anstee pointed out that in $80 \%$ of cases postnatal exchange transfusion was not required when the foetus had been transfused prenatally for severe disease. ${ }^{37}$

Sproul et al noticed that the exchange transfusion removed $25 \%$ of circulating bilirubin and $70 \%-90 \%$ antibody coated red cells. They also observed that rapid rebound of serum bilirubin level was common after equilibration and required additional exchange transfusions. ${ }^{38}$

Erythropoiesis might be suppressed for many months after exchange transfusion giving a false impression of red cell aplasia.

Blood component therapy was required in infants with Rh-D HDFN and they needed 9 units of PRC, 3 units of platelets and 2 units of FFP. In accordance to literature review, thrombocytopenia was common, especially after exchange transfusions in Rh-HDFN.

When intensity of treatment was analysed, $45.5 \%$ of infants with Rh-D HDFN required no treatment (grade-0). Few required more intensive treatment (grade 3 and 4). Anaemia was significantly associated with increased duration of stay in ICU in case of infants with Rh-D HDFN. Similarly, Bowman JM found out that at birth, about half of the affected infants had no or mild anaemic, no dangerous hyperbilirubinaemia and required no treatment. ${ }^{23}$

He also observed that $25 \%$ of affected infants were extremely jaundiced and developed kernicterus or died. ${ }^{23} \mathrm{~A}$ low reticulocyte count was observed by Koenig in foetuses treated with intrauterine transfusion. ${ }^{38}$ Vidnes J and Finne $\mathrm{H}$ established that the severity of haematologic abnormalities in Rh-D haemolytic disease was directly proportional to the severity of ${ }^{39}$ haemolysis.

Koenig JM saw that thrombocytopenia was common in Rh-D haemolytic disease after intrauterine or exchange transfusions. He also found out that hypoglycaemia was seen in infants with Rh-D haemolytic disease due to islet cell hyperplasia and hyperinsulinism, secondary to release of metabolic byproducts such as glutathione from lysed red cells.

During follow-up after two weeks, two infants with Rh-D HDFN were readmitted for treatment of hyperbilirubinaemia. One Rh-D HDFN baby had anaemia necessitating readmission. In contrast Bel Cosmos et al observed that newborn with RhD HDFN did not have significant anaemia during first three months of life after disease period.

The research was descriptive one and had limitation in assessing the risk and correlation. Long term analytical studies with more numbers of samples are necessitated for getting more solid information.

\section{CONCLUSION}

1. Male infants had higher risk of developing Rh-D HDFN.

2. Hyperbilirubinaemia and anaemia was milder in majority of neonates.

3. Disease was mild among $3 / 4^{\text {th }}$ of infants and almost half of the infants required no treatment.

4. High bilirubin levels were associated with anaemia and anaemia was associated with longer stay in ICU.
5. Cord blood haemoglobin levels were negatively correlated with intensity of treatment and severity of disease.

6. Peak bilirubin levels were positively correlated with severity of disease, intensity of treatment and stay in ICU and negatively correlated with cord blood haemoglobin.

\section{ACKNOWLEDGEMENT}

We acknowledge Dr. Anupa Lucas, Dr. Rajany Jose and Dr. Reshmi Ramachandran, Assistant Professors in Dept. of Community Medicine, Govt. Medical College, Thrissur, for their unwavering support and perpetual inspiration in this research. We offer our sincerest obligation to Dr. Lalitha Kailas, Professor and HOD in Dept. of Paediatrics, Gokulam Medical College, Trivandrum, and Dr. Shobha Kumar, Professor in Dept. of Paediatrics, Govt. Medical College, Trivandrum, for their scholarly guidance in the course of this work.

\section{REFERENCES}

[1] Harmening DM. Modern blood banking and transfusion practices. $5^{\text {th }}$ edn. F A Davis Company and Jaypee Publications 2005:P 383.

[2] Solheim BG, Grönn M. Hemolytic disease of the fetus and newborn. Rossi's principles of transfusion medicine. $4^{\text {th }}$ edn. Blackwell Publishing Ltd 2009:P 418.

[3] Greer JP, Foerster J, Rodgers GM, et al. Wintrobe's clinical hematology. $12^{\text {th }}$ edn. Lippincott Williams \& Wilkins 2009:P 982.

[4] Hadley AG, Wilkes A, Goodrick J, et al. The ability of the chemiluminescence test to predict clinical outcome and the necessity for amniocenteses in pregnancies at risk of haemolytic disease of the newborn. BJOG: An International Journal of Obstetrics \& Gynaecology 1998;105(2):231-4.

[5] Greer JP, Foerster J, Rodgers GM, et al. Wintrobe's clinical hematology. $12^{\text {th }}$ edn. Lippincott Williams \& Wilkins 2009:P 992.

[6] Klein H, Anstee D. Mollison's blood transfusion. In: clinical medicine. $11^{\text {th }}$ edn. Blackwell Publishing Ltd 2005:P 507.

[7] Walker W, Murray S, Russell JK. Stillbirth due to haemolytic disease of the newborn. J Obstet Gynaecol Br Emp 1957;64(4):573-81.

[8] Nevanlinna HR. Factors affecting maternal Rh immunization. Ann Med Exp Fenn 1953;31(2):1-80.

[9] Simonovits I, Timár I, Bajtai G. Rate of Rh immunization after induced abortion. Vox Sang 1980;38(3):161-4.

[10] Matthews CD, Matthews AE. Transplacental haemorrhage in spontaneous and induced abortion. Lancet 1969;1(7597):694-5.

[11] Hocevar M, Glonar L. Rhesus factor immunization. In: The ljubljana abortion study 1971-1973. Ardolsek L (edr). Maryland: national institute of health center for population research 1974.

[12] Grant CJ, Hamblin TJ, Smith DS, et al. Plasmapheresis in $\mathrm{Rh}$ hemolytic disease: the danger of amniocentesis. Int J Artif Organs 1983;6(2):83-6. 
[13] Warren RC, Butler J, Morsman JM, et al. Does chorionic villus sampling cause fetomaternal haemorrhage? Lancet 1985;325(8430):691.

[14] Allen FH. Induction of labor in the management of erythroblastosis fetalis. Q Rev Pediat 1957;12(1):1-5.

[15] Renkonen KO, Timonen S. Factors influencing the immunization of Rh-negative mothers. J Med Genet 1967;4(3):166-8.

[16] Scott JR. Immunologic risks to fetuses from maternal to fetal transfer of erythrocytes. In: Proceedings of symposium on $\mathrm{Rh}$ antibody mediated immunosuppression. Raritan, NJ: Ortho Research Institute 1976.

[17] Renkonen KO, Seppälä M. The sex of the sensitizing Rh-positive child. Ann Med Exp Fenn 1962;40:108.

[18] Mollison PL, Cutbush M. A method of measuring the severity of a series of cases of hemolytic disease of the newborn. Blood 1951;6:777-88.

[19] Ackerman BD, Dyer GY, Leydorf MM. Hyperbilirubinemia and kernicterus in small premature infants. Pediatrics 1970;45(6):918-25.

[20] Polácek K. The clinical assessment of haemolytic disease of the newborn. Arch Dis Child 1955;30(151):217-23.

[21] Bowman JM. Hemolytic disease (erythroblastosis fetalis). In: Creasy RK, Resnik R. Maternal-fetal medicine. $4^{\text {th }} \quad$ edn. Philadelphia: WB Saunders 1999:736-67.

[22] Nicolaides KH, Rodeck CH, Millar DS, et al. Fetal haematology in rhesus isoimmunisation. BMJ 1985;290:661-3.

[23] Armitage P, Mollison PL. Further analysis of controlled trials of treatment of haemolytic disease of the newborn. J Obstet Gynaecol Br Emp 1953;60(5):60520.

[24] Mollison PL, Cutbush M. Haemolytic disease of the newborn: criteria of severity. BMJ 1949;1(4594):12330 .

[25] Crawford H, Cutbush M, Mollison PL. Hemolytic disease of the newborn due to anti-A. Blood 1953;8(7):620-39.

[26] Hughes-Jones NC, Hughes MIJ, Walker W. The amount of anti-D on red cells in haemolytic disease of the newborn. Vox Sang 1967;12(4):279-85.
[27] Levine P, Vogel P, Rosenfield RE. Hemolytic disease of the newborn. Adv Pediatr 1953;6:97-156.

[28] Cremer RJ, Perryman PW, Richards DH. Influence of light on the hyperbilirubinaemia of infants. Lancet 1958;1(7030):1094-7.

[29] American Academy of Pediatrics clinical practice guideline Subcommittee on Hyperbilirubinemia. Management of hyperbilirubinemia in the newborn infant 35 or more weeks of gestation. Pediatrics 2004;114(1):297-316.

[30] Kaplan E, Herz F, Scheye E, et al. Phototherapy in ABO hemolytic disease of the newborn infant. The Journal of Pediatrics 1971;79(6):911-4.

[31] Rubo J, Wahn V. High-dose intravenous gammaglobulin in rhesus-haemolytic disease. Lancet 1991;337(8746):914.

[32] Figueras-Aloy J, Rodriguez-Miguelez JM, Iriondo-Sanz $\mathrm{M}$, et al. Intravenous immunoglobulin and necrotizing enterocolitis in newborns with hemolytic disease. Pediatrics 2010;125(1):139-44.

[33] Allen FH, Diamond LK, Vaughan VC III. Erythroblastosis fetalis, VI. Prevention of kernicterus. Am J Dis Child 1950;80(5):779-91.

[34] Klein H, Anstee D. Mollison's blood transfusion. In: clinical medicine. $11^{\text {th }}$ edn. Blackwell Publishing Ltd 2005:P 520.

[35] Sproul A, Smith L. Bilirubin equilibration during exchange transfusion in hemolytic disease of the newborn. J Pediatr 1964;65:12-26.

[36] Klein H, Anstee D. Mollison's blood transfusion. In: clinical medicine. $11^{\text {th }}$ edn. Blackwell Publishing Ltd 2005:P 519.

[37] Koenig JM. Evaluation and treatment of erythroblastosis fetalis in the neonate. In: Christensen $\mathrm{R}$, (edr). Hematologic problems of the neonate. Philadelphia, Pa: WB Saunders 2000:185207.

[38] Vidnes J, Finne H. Immunoreactive insulin in amniotic fluid from Rh-immunized women. Biol Neonate 1977;31(1-2):1-6.

[39] Comos BJ, Crusafont RA, Pujol NA, et al. Value of the coombs test in ABO incompatibility. J An Esp Pediatr 1991;35(4):248-50. 